\title{
The Effect of Child Care and Feeding Practices on the Nutritional Status of Children of Market Women in Ondo State, Nigeria.
}

\author{
Bolajoko O. O.and Ogundahunsi G. A. \\ (Department of Nutrition and Dietetics, Rufus Giwa Polytechnic, Owo, Ondo State, Nigeria)
}

\begin{abstract}
Optimal infants and young children feeding is paramount to their health and nutritional status. This study assessed the childcare and feeding practices among 200 market women in relation to their children nutritional status. Semi-structured questionnaire was used to collect information on childcare and feeding practices; anthropometric indices of 200 infants were also taken and analyzed. The result showed that $98 \%$ of the market women initiated breastfeeding immediately after delivery, 99\% practiced exclusive breastfeeding and majority of the women take their children along with them to the market. The major complementary staple used by the women was sorghum (53.6\%), $62 \%$ of the respondents admitted the use of soybean powder as the major protein source in the gruel. The mean age, weight, height and MUAC of the infants were respectively 20months, $10 \mathrm{~kg}, 78 \mathrm{~cm}$, and $14 \mathrm{~cm}$. The study revealed that $31 \%$ of the children were moderately stunted and $39 \%$ were moderately underweight. The duration of breastfeeding and childcare practices were found to significantly affect nutritional status at $p<0.05$. Therefore, mothers should be properly educated on the appropriate combination of local staples for complementary foods through food demonstration class during post natal clinic.
\end{abstract}

Keywords - Exclusive breastfeeding, complementary feeding, gruel, stunting, underweight.

\section{Introduction}

Optimal infant and young child-feeding (IYCF) practice is crucial for nutritional status, growth, development, health and ultimately the survival of the infant and young children ${ }^{[1]}$. Worldwide, sub-optimal breastfeeding still accounts for deaths of 1- 4million children aged less than five years (under-five mortality) ${ }^{[1]}$. The poor complementary feeding practices means that many children continue to be vulnerable to irreversible outcome of stunting, poor cognitive development, and significantly increased risk of infectious diseases such as acute respiratory infection and diarrhea ${ }^{[2]}$. The inadequate nutrition education among women of child-bearing age and inadequate health services, beliefs, lack of confidence to put knowledge into practice in the face of myths and superstition challenge the survival, growth and the development of children ${ }^{[3]}$.

In a developing country like Nigeria with a high burden of diseases and low access to safe water and sanitation even in developed countries recent studies have underscored the role of IYCF practice in reducing mortality ${ }^{[4]}$. This study is a baseline study that provides data and information on childcare and infant feeding practices among the market women and the nutritional status of their children.

\section{Materials And Method}

The study was a survey of market women and their children under 24 months of age in markets in Ondo State. Three major markets were randomly selected and only women who were nursing children under 24 months were selected, 200 women and 200 children were used for the study. Pretested semi-structured questionnaire was used to elicit information on demographic status, child-care, breastfeeding and complementary feeding practices. Anthropometric indices were also measured using standard procedure by Maxiya-Dixon et al, $(2004)^{[5]}$. Data collected was analyzed using Epi-info nutritional anthropometry software ${ }^{[6]}$ to determine BMI, height for age, weight for age percentiles and Z-scores, CDC/WHO reference growth chart standards were used to determine cut-offs. SPSS version 17 was used to analyze demographic and child-care practices data.

\section{Results}

The study revealed that all the respondents breastfed their children, and the practice of exclusive breastfeeding (EBF) was 99\%, all the mothers initiated breastfeeding in less than one hour after delivery.

Table 1 shows that the mothers introduce their infant to complementary food at six month, the food majorly used as complementary food was gruels from sorghum (53.3\%) followed by cerelac (17.5\%), and maize was $(11 \%)$. 
Table 1 Complementary food of the respondents

\begin{tabular}{lll}
\hline Complementary Foods & $\mathbf{N}$ & \% \\
\hline Maize gruel & 22 & 11.3 \\
Sorghum gruel & 104 & 53.6 \\
Cerelac & 34 & 17.5 \\
Nutriend & 6 & 3.0 \\
Beans (mashed) & 8 & 4.0 \\
Others & 20 & 10.0 \\
\hline
\end{tabular}

Table 2 shows the major protein source of the complementary foods given to the children, $62.8 \%$ of the mothers use soy bean power while $26.6 \%$ use groundnut and crayfish was used by $6.4 \%$ of the respondents.

Table 2 Major protein source of the complementary foods

\begin{tabular}{lll}
\hline Protein sources & $\mathbf{N}$ & $\%$ \\
\hline None & 6 & 2.1 \\
Groundnut & 50 & 26.6 \\
Crayfish & 12 & 6.4 \\
Soybean powder & 119 & 62.8 \\
\hline
\end{tabular}

Table 3 shows the childcare practices of the subjects, most of the market women (90\%) reported taking their children along to the market while $10 \%$ took theirs to daycare.

Table 3 Child care center

\begin{tabular}{lll}
\hline Child Care Center & $\mathbf{N}$ & $\%$ \\
\hline Daycare & 20 & 10.0 \\
With me in the market & 180 & 90.0 \\
\hline
\end{tabular}

Table 4 shows anthropometry assessment of the children, the means of their ages, weight, height and mid upper arm circumference (MUAC) were respectively 20 months, $10 \mathrm{~kg}, 78 \mathrm{~cm}$ and $14.68 \mathrm{~cm}$.

Table 4 Means of Anthropometry Indices

\begin{tabular}{ll}
\hline Indices & Mean \\
\hline Age (month) & $20 \pm 3$ \\
Height $(\mathrm{cm})$ & $78.2 \pm 8$ \\
Weight $(\mathrm{kg})$ & $10.3 \pm 3$ \\
MUAC $(\mathrm{cm})$ & $14.68 \pm 2$
\end{tabular}

Table 5 shows the height-for-age (z-score range) of the subjects, it reflected that $31 \%$ were moderately stunted while the weight for age $\mathrm{z}$-score showed that $39 \%$ of the children were underweight. However, duration of breastfeeding and childcare practices were found to significantly affect nutritional status at $\mathrm{p}<0.05$.

Table 5 Nutritional Status of the Subject

\begin{tabular}{lll}
\hline Nutritional status & N & \% \\
\hline Stunting & 62 & 31 \\
Underweight & 78 & 39 \\
\hline
\end{tabular}

\section{Discussion}

All the respondents breastfed their children, and the practice of exclusive breastfeeding was $99 \%$, this is due to the establishment of mother and child hospitals by the Ondo State Government where anti-natal and post-natal clinics were run free of charge. This perfectly agrees with the work of Ene-Obong et al $(2001)^{[7]}$ who reported that most market women exclusively breastfed their children. Also Abidoye (1993) ${ }^{[8]}$ in his work said $72 \%$ of the market woman practice EBF.

Moreover, all the mothers initiated breastfeeding in less than one hour after delivery. This is because all of them had their babies in the hospital. This correlates with the work of Alutu and Onubu $2005^{[9]}$ who have observed that $98 \%$ started breastfeeding almost immediately after delivery and fed colostrum to their babies. 
Also, majority of the respondents practice exclusive breastfeeding (99\%). This is an improvement from the past researches which show practice of exclusive breastfeeding to be less than $50 \%{ }^{[10]}$ also Aghaji $(2002)^{[11]}$ show that mothers knowledge of exclusive breastfeeding may improve the practice of EBF. It is a known fact that mother and child programme in the state comprehensively educate mothers on EBF.

The mothers introduce their infant to complementary food at six month, the food majorly used as complementary food was gruel from sorghum $(53.3 \%)$. This agrees with Ene-Obong et al (2001) ${ }^{[7]}$ in their study who showed that $70 \%$ of the market women used sorghum gruel as the major complementary food for their infants. The major source of protein in the gruel was soybean powder with $62.8 \%$.

The assessment of nutritional status of the children reflected that $31 \%$ were moderately stunted. This is quite higher than Abidoye's report in $1993^{[8]}$ who said that $20 \%$ of the children of the market women were moderately stunted. Moreover, $39 \%$ were moderately underweight. This is in agreement with the work of Abidoye $(1993)^{[8]}$ who said $39.2 \%$ of the children of the market women were underweight on the contrary, this is higher than the $\mathrm{WHO}^{[12]}$ estimate in 2008 which was $26.7 \%$. The duration of breastfeeding and childcare practice were found to significantly affect nutritional status at $\mathrm{p}<0.05$.

\section{Conclusion}

It was found from the study that the prevalence of stunting and underweight was still high among the children and the adequacy of the nutrients of the complementary foods given was not ascertained. Also the foods given lack variety because mothers are not grounded on proper combination of local staples to prepare complementary foods and malnutrition still poses a great threat to health and proper development of these children.

\section{Recommendation}

Market women should be empowered by giving micro credit to them to expand their businesses and improve their socio-economic status so as to enhance good standard of living. Also, mothers should be properly educated on the appropriate combination of local staples for complementary food for children of six months and above through food demonstration classes during post-natal clinic.

\section{References}

[1]. Blutta ZA, Ahmed t, Black RE, Cousen S, Deve K, interventions for maternal and child under-nutrition and survival. 2008 pg $22-27$

[2]. ACC/SCN. 4th Report on the world nutrition situation. Nutrition throughout the life cycle. United Nations Administrative Committee on Nutrition (ACC/SCN) in collaboration with International Food Policy Research Institute (IFPRI). 2000 pp: 4-12.

[3]. Ijarotimi QS. Assessing exclusive breastfeeding practices, dietary intake and BMI of nursing mothers in Ekiti State. Pub. Med Journal 4(3) 2010, 222-8.

[4]. Chen A, Rogan W, J Breastfeeding and the Postneonatal Death in United State. Journal of the American Academy of Pediatrics. 113(5). 2004, 435-439.

[5]. Maxiya-Dixon, B., Oguntona, E. B., Harris, E., Nokoe, S., Manyong, V., Akinyele. I. O. and Sanusi, R. A.. Nigeria food consumption and nutrition survey 2001-2003. Food Instruction Booklet. Ibadan, Nigeria. 2006.

[6]. Dean, A.G. and Arner, T.G., .(1999). Epi-info 2000: A database and statistics program for public health professionals. Epidemiology program office. Mailsiop K74 CDC, Atlanta, On 3034-3717.

[7]. Ene-Obong HN, Enugu GI, Uwaegbute AC. Determinants of health and nutritional status of rural Nigerian women.J Health Popul Nutr $19,2001,320-330$

[8]. Abidoye R The of on the nutritional status of infant in Sagamu, Ogun State. Journal of Community Medicine and Primary Health Care, Vol. 5, 1993, pp.65-69

[9]. Alutu E, Onibu O. Barrier of EBF practices among rural and urban nursing mother in Edo state in Nigeria, implementation of education and culture research work. 21(22), 2004. pp 22-25.

[10]. Ogbonna C, Daboer JC: Current knowledge and practices of Ebf among mothers in Jos, Nigeria. Niger J. Med. 16(3), 2007. 256-60.

[11]. Aghaji M. exclusive breastfeeding practice and associated factors in Enugu state, Nigeria. 21(1), 2002. pp 66-99.

[12]. World Health Organization, Global Database on Child Growth and Malnutrition. 2008 